\title{
Effectiveness and safety of high-dose valsartan monotherapy in hypertension treatment: the ValTop study
}

\author{
Gianfranco Parati ${ }^{1,2}$, Roland Asmar ${ }^{3}$, Grzegorz Bilo ${ }^{1,2}$, Albert Kandra ${ }^{4}$, Robert Di Giovanni ${ }^{4}$ and \\ Thomas Mengden ${ }^{5}$
}

Early combination therapy is increasingly recommended in hypertension management because of increased risk of adverse effects with high-dose monotherapy. However, this risk is not necessarily increased for high doses of angiotensin receptor blockers (ARB). ValTop study compared efficacy and safety of high vs. conventional dose of valsartan in hypertensive patients. ValTop was a controlled, randomized, double-blind trial. Of 6035 screened subjects, 4004 mild-to-moderate hypertensive patients (mean seated diastolic blood pressure (MSDBP) $90-109 \mathrm{~mm} \mathrm{Hg}$ ) started 4-week open-label treatment with valsartan $160 \mathrm{mg}$. Of them, 3776 were randomized to receive valsartan $160 \mathrm{mg}(N=1900)$ or $320 \mathrm{mg}(N=1876)$ o.d. for 4 weeks. In 28-week open-label extension study, all participating patients $(N=642)$ received valsartan $320 \mathrm{mg}$. Valsartan $160 \mathrm{mg}$ reduced MSDBP by $10.0 \mathrm{~mm} \mathrm{Hg}$ in the initial open-label phase. Further BP reductions in the double-blind phase were significantly $(P<0.0001)$ greater in the $320 \mathrm{mg}$ group than in the $160 \mathrm{mg}$ group for MSDBP $(1.6 \pm 0.18 \mathrm{~mm} \mathrm{Hg} v \mathrm{~s} .0 .5 \pm 0.18 \mathrm{~mm} \mathrm{Hg})$ and mean seated systolic BP $(3.3 \pm 0.31 \mathrm{~mm} \mathrm{Hg} v s .0 .7 \pm 0.31 \mathrm{~mm} \mathrm{Hg})$. The size of the additional effect of the $320 \mathrm{mg}$ dose on BP was similar in subjects controlled or not by the initial $160 \mathrm{mg}$ dose. Adverse event (AE) rates were similar in both treatment groups, drug-related AEs occurring in $<5 \%$ of subjects in each phase. High-dose valsartan is safe and effective in uncomplicated mild-to-moderate hypertension independently of the initial response to a moderate dose. High-dose ARB monotherapy may thus be a viable option in hypertension management.

Hypertension Research (2010) 33, 986-994; doi:10.1038/hr.2010.120; published online 5 August 2010

Keywords: angiotensin receptor blockers; antihypertensive therapy; arterial hypertension; clinical trials; monotherapy

\section{INTRODUCTION}

Hypertension is one of the main public health problems worldwide, because of its prognostic consequences and its high prevalence in a variety of populations. ${ }^{1,2}$ Although the beneficial effects of reducing blood pressure (BP) to levels recommended by guidelines have been clearly shown, ${ }^{3}$ still, control rates of hypertension remain low. ${ }^{1,2,4}$ This is at least in part related to problems such as physician inertia and poor patient compliance with treatment, which has prompted the research of appropriate therapeutic strategies that might minimize their negative impact.

The traditional approach to pharmacological treatment of hypertension is based on an initial monotherapy followed by dose uptitration and/or addition of other drugs. Recently, the early use of combination therapy has been more strongly recommended. ${ }^{1,2,5}$ However, introducing an additional drug is not always an ideal solution: on one hand, relatively healthy patients are frequently reluctant to take an additional pill, which may lower their compliance; on the other hand, in elderly patients who already take a number of different drugs, a further increase in the number of pills may become a serious problem (allergies, drug interactions, reduced compliance), which, if possible, should be avoided. Fixed-dose combinations may only in part address these issues as they limit the dosing flexibility of individual drugs and they do not resolve the problems associated with polypragmasy.

Although high-dose monotherapy to achieve BP targets is not feasible for many drugs because of a concomitant increased risk of dose-dependent adverse effects, this may not be the case for angiotensin receptor blockers (ARBs), which have been suggested to effectively lower BP without an associated increased risk of adverse side effects even at high dosages. Furthermore, high-dose administration of these drugs has been proposed because of the demonstrated prognostic benefits independent of BP lowering. This, however, was mainly shown in special populations (congestive heart failure, myocardial infarction, renal failure) whereas, to our knowledge, large

\footnotetext{
${ }^{1}$ Department of Clinical Medicine and Prevention, University of Milano-Bicocca, Milan, Italy; ${ }^{2}$ Department of Cardiology, S.Luca Hospital, IRCCS, Istituto Auxologico Italiano, Milan, Italy; ${ }^{3}$ L'Institut CardioVasculaire, Paris, France; ${ }^{4}$ Novartis Pharma AG, Basel, Switzerland and ${ }^{5}$ Division of Hypertension and Vascular Medicine, University Clinic Bonn, Medical Clinic II, Bonn, Germany

Correspondence: Professor G Parati, Istituto Scientifico Ospedale San Luca, Istituto Auxologico Italiano, via Spagnoletto 3, Milan 20149, Italy.

E-mail: gianfranco.parati@unimib.it

Received 10 December 2009; revised 23 April 2010; accepted 10 May 2010; published online 5 August 2010
} 
size trials on the administration of high-dose ARBs in uncomplicated hypertensives are lacking. ${ }^{6-10}$ In particular, no data are available on BP-lowering efficacy of high dose of valsartan $(320 \mathrm{mg})$ in patients initially treated with valsartan $160 \mathrm{mg}$ who displayed a limited response to the initial dose.

On this background, we hypothesized that, when the alternatives to combination therapy of hypertension are considered, use of high-dose monotherapy with ARBs (specifically with valsartan) may be a safe and effective way of improving BP control in subjects with a limited response to the initial monotherapy in the standard dosage, without worsening of drug tolerability. The aim of this study was to verify this hypothesis in patients with uncomplicated diastolic essential hypertension.

\section{METHODS}

The ValTop study consisted of two main phases: a double-blind core trial and an open-label extension study. The core trial was a multi-center, randomized, double-blind, active-controlled, parallel-group study, stratified according to the patients' BP control status after 4 weeks of treatment with valsartan $160 \mathrm{mg}$. It consisted of three phases:

- A 2-week screening period for determining patient eligibility and washout of medication not allowed by protocol.

- 4-week open-label treatment with valsartan $160 \mathrm{mg}$.

- 4-week double-blind treatment with either 160 or $320 \mathrm{mg}$ valsartan.

Patients were stratified according to their mean seated diastolic BP (MSDBP) after the open-label period to Stratum 1 (controlled: MSDBP $<90 \mathrm{~mm} \mathrm{Hg}$ ) and Stratum 2 (not controlled: MSDBP $\geqslant 90 \mathrm{~mm} \mathrm{Hg}$ ). Within each stratum, patients were randomized to receive either valsartan 160 or $320 \mathrm{mg}$ treatment in a 1:1 ratio. The core trial was followed by a 28 -week open-label extension during which all patients received valsartan $320 \mathrm{mg}$.

The study was designed, implemented and reported in accordance with the International Conference on Harmonization Tripartite Guidelines for Good Clinical Practice, with applicable local laws and regulations and with the ethical principles laid down in the Declaration of Helsinki. Study protocol was approved by local Ethics Committees of participating institutions.

\section{Participants}

Eligible for participation in the core trial were male and female outpatients between the ages of 18 to 80 years, with mild-to-moderate hypertension (grades 1 or 2 WHO classification), who gave written informed consent to participate in the study. At washout, all treatment-naive patients needed to have MSDBP $\geqslant 95$ and $\leqslant 109 \mathrm{~mm} \mathrm{Hg}$, and earlier treated patients needed to have MSDBP $\leqslant 109 \mathrm{~mm} \mathrm{Hg}$. At the start of the open-label period, all patients needed to have MSDBP $\geqslant 95$ and $\leqslant 109 \mathrm{~mm} \mathrm{Hg}$.

Patients with any of the following were excluded from the study: severe hypertension (grade 3 by WHO); malignant hypertension; inability to discontinue safely earlier antihypertensive medications; history of proteinuria ( $>0.3 \mathrm{~g}$ per $24 \mathrm{~h}$ ); potentially fertile female patients not using effective contraceptive methods; history of hypertensive encephalopathy or cerebrovascular accident; secondary hypertension; type 1 diabetes mellitus; type 2 diabetes mellitus with poor glycemic control; other significant cardiovascular disease; thyroid medication, unless in a stable replacement therapy; upper arm circumference $>42 \mathrm{~cm}$; unwillingness or inability to give informed consent.

Patients who successfully completed the core study (in compliance with the protocol, with randomization code was kept blinded and without serious adverse events (AEs)), who had a mean seated systolic BP (MSSBP) $>110 \mathrm{~mm} \mathrm{Hg}$ at the end of the double-blind period and who gave written informed consent were eligible for participation in the extension study.

The study was performed in 303 centers in 24 countries (listed in Appendix).

\section{Study medication}

Study drugs were always administered once daily in the morning. Patients took two capsules of valsartan $80 \mathrm{mg}$ during the initial open-label phase. After randomization, patients took two capsules of double-blind medication (valsartan 80 or $160 \mathrm{mg}$ ). During the open-label extension, patients took two capsules of valsartan $160 \mathrm{mg}$.

During the core trial, the use of other antihypertensive drugs or diuretics was excluded. There was no restriction regarding concomitant medication use during the open-label extension study.

\section{Objectives}

The primary objective of the core trial was to assess the BP-lowering effect of 4-week treatment with a once-daily monotherapy of valsartan $320 \mathrm{mg}$, compared with valsartan $160 \mathrm{mg}$, in patients with uncomplicated essential diastolic hypertension (MSDBP $\geqslant 95 \mathrm{~mm} \mathrm{Hg}$ and $\leqslant 109 \mathrm{~mm} \mathrm{Hg}$ ) stratified according to MSDBP control achievement with the initial valsartan $160 \mathrm{mg}$ monotherapy.

The secondary objective was to assess the BP-lowering effect of 4-week treatment with once-daily valsartan $320 \mathrm{mg}$ compared with valsartan $160 \mathrm{mg}$ in subjects not controlled with $160 \mathrm{mg}$ dose (Stratum 2). The tertiary objectives were to assess the BP-lowering effect of 4-week treatment with once-daily valsartan $320 \mathrm{mg}$ compared with valsartan $160 \mathrm{mg}$ in subjects controlled with $160 \mathrm{mg}$ dose (Stratum 1), and to evaluate the short-term safety of valsartan $320 \mathrm{mg}$ treatment.

The objective of the extension study was to assess the maintenance of therapeutic effectiveness, tolerability and safety of long-term treatment with valsartan $320 \mathrm{mg}$ in an open-label manner.

\section{Outcomes}

The primary outcome in the core study was the change in trough MSDBP from baseline to end point (end of follow-up) in the overall population. Secondary outcome was the change in trough MSDBP in subjects not controlled with $160 \mathrm{mg}$ once daily. Tertiary outcomes included change in trough MSDBP in subjects controlled with $160 \mathrm{mg}$ once daily; change in trough MSSBP; change in mean seated pulse pressure, response and control rates in the overall population, in subjects controlled or not by initial open-label treatment. BP response was defined for systolic BP as MSSBP $<140 \mathrm{mmHg}$ or a reduction of $\geqslant 20 \mathrm{~mm} \mathrm{Hg}$ from baseline and for diastolic BP as MSDBP $<90 \mathrm{~mm} \mathrm{Hg}$ or a reduction of $\geqslant 10 \mathrm{~mm} \mathrm{Hg}$ in MSDBP from baseline. BP control was defined for systolic BP as MSSBP $<140 \mathrm{~mm} \mathrm{Hg}$ and for diastolic BP as MSDBP $<90 \mathrm{~mm} \mathrm{Hg}$. The primary end point of the extension study was the change in trough MSDBP and MSSBP between randomization and final visit (28 weeks).

Safety assessments consisted of monitoring and recording all AEs (with their severity and relationship to study drug). It also included regular monitoring of hematology, blood chemistry and urine performed at a central laboratory, and regular assessments of vital signs, physical condition and body weight.

To assess compliance with treatment, drug accountability was noted by the field monitor during site visits and at the completion of the trial.

\section{BP measurement}

A detailed description of BP measurement procedures will be published in a companion methodological paper. ${ }^{11}$ In brief, at each visit, sitting BP was measured at trough ( $24 \pm 3 \mathrm{~h}$ post-dose) with a validated, electronic, automated oscillometric device (Omron 705IT, Omron, Kyoto, Japan) ${ }^{12}$ three times at 1- to 2-min intervals and the mean of all three measurements was used in the analyses. The subject had to be seated for $5 \mathrm{~min}$ with the arm positioned on the table and the cuff at the heart level. If at the initial visit a significant difference in BP was found between arms ( $\geqslant 10 \mathrm{~mm} \mathrm{Hg}$ in systolic BP and/or $\geqslant 5 \mathrm{~mm} \mathrm{Hg}$ in diastolic BP), the arm with higher BP was used, otherwise the non-dominant arm was used. The same arm was used at all subsequent visits. If a difference between the highest and lowest BP readings exceeded $10 \mathrm{~mm} \mathrm{Hg}$ for systolic BP or $5 \mathrm{~mm} \mathrm{Hg}$ for diastolic BP, the set of three readings was repeated after $3 \mathrm{~min}$.

\section{Sample size}

The sample size and power calculation were based on the primary variable, change from baseline in trough MSDBP. The sample size was determined to ensure $85 \%$ power for not controlled patients. The power for the overall population was derived from this and was calculated as $98 \%$. An s.d. of 
$8 \mathrm{~mm} \mathrm{Hg}$ for the difference from baseline in diastolic BP, an $\alpha$-level for statistical significance of 0.05 (two sided) and an expected difference of $1.2 \mathrm{~mm} \mathrm{Hg}$ between groups were assumed. Assuming $10 \%$ dropout rate, a total of 1780 patients with MSDBP $\geqslant 90 \mathrm{~mm} \mathrm{Hg}$ at randomization visit (not controlled) were required. As the expected rate of not controlled subjects was $55 \%$, around 3236 patients were needed to enter the run-in period. The actual number of not controlled subjects during a blinded interim review was close to $50 \%$ and, therefore, the sample size was adjusted to have a least 3560 randomized patients. Sample size calculations were performed using the nQuery Advisor software (Statistical Solutions, Saugus, MA, USA).

\section{Randomization and blinding}

Patients were stratified based on whether they were controlled with open-label valsartan $160 \mathrm{mg} \quad(\mathrm{MSDBP}<90 \mathrm{~mm} \mathrm{Hg}$, Stratum 1) or not (MSDBP $\geqslant 90 \mathrm{~mm} \mathrm{Hg}$, Stratum 2) and were randomized within each stratum in a 1:1 ratio to either valsartan 160 or $320 \mathrm{mg}$ per day. Randomization was performed by Novartis Drug Supply Management using a validated system. The randomization scheme was reviewed by a Biostatistics Quality Assurance Group and locked by them after approval. Throughout the study, randomization data were kept strictly confidential, accessible only to authorized persons. Only when the study had been completed, the data file verified, and the protocol violations determined were the drug codes broken and made available for data analysis. The double blind during the core study was maintained by the use of capsules of identical appearance for both study drug strengths.

\section{Statistical methods}

In the double-blind period, the BP efficacy parameters (MSDBP, MSSBP and mean pulse pressure) were examined in the overall intent-to-treat (ITT) population (all patients randomized, who provided baseline efficacy data and from whom at least one post-baseline efficacy measurement (MSDBP and MSSBP) was obtained after randomization), in both study strata. The primary, secondary and tertiary efficacy analyses were carried out for the ITT population and the primary analysis was repeated for the per-protocol population (all ITT patients who completed the study without any major deviations from the protocol procedures). Summary statistics of MSDBP, including the mean change from baseline (week 0) for the overall population, as well as for controlled and not controlled stratum, are presented for week 4 and end point by the treatment group. The change in primary, secondary and tertiary efficacy outcomes was analyzed using analysis of covariance with treatment, center and control stratum as fixed factors and (centered) baseline MSDBP measurement as covariate. Centers with $<3$ patients per treatment group were pooled within a country. In the analysis of control and responder rates, a logistic regression model was fitted with treatment and control stratum (where appropriate) as factors. Maximum likelihood estimates along with $95 \%$ confidence intervals (Wald confidence limits) for the odds ratios of valsartan $320 \mathrm{mg}$ vs. $160 \mathrm{mg}$ were calculated. The assessment of safety was based on the frequency of AEs and on the number of laboratory values that fell outside of pre-determined ranges.

\section{RESULTS}

\section{Study participants}

A total of 4004 eligible patients in 24 countries were enrolled into the open-label run-in phase of the study, and 3776 were randomized into the double-blind phase between 10 November 2003 and 2 December 2004, the most common reasons for discontinuation were AEs, protocol violation and withdrawal of consent. Numbers of patients randomized, completed and discontinued in the double-blind phase did not differ between the treatment groups. This portion of the study was completed by $98.6 \%$ of subjects, the most common reasons for discontinuation being protocol violation and AEs, similarly in both treatment groups.

A total of 642 patients participated in the extension phase of which $92.7 \%$ completed this portion of the study, the most common reasons for discontinuation being AEs, withdrawal of consent and unsatisfactory therapeutic effect. The two core treatment groups were evenly represented in the extension phase (Figure 1).

The treatment groups were comparable with respect to the demographic characteristics as well as BP values at baseline (Table 1). The majority of the patients were Caucasian with a slight majority of men $v s$. women. The mean age was 54.9 years, with $81.8 \%$ of patients younger than 65 years of age. Approximately two thirds $(65.6 \%)$ of the patients received antihypertensive treatment before entering the study. The most frequently used drugs were ACE inhibitors $(21.3 \%)$, selective $\beta$-blocking agents (14.9\%), dihydropyridine calcium channel blockers (12.5\%), angiotensin II antagonists $(11.3 \%)$, diuretics (thiazides) $(6 \%)$, angiotensin II antagonists and diuretics in combination (6.8\%) and ACE inhibitors and diuretics in combination $(4.2 \%)$.

Demographic characteristics for controlled and not controlled subjects were similar as in the overall ITT population. Demographic characteristics of patients in the extension phase were similar to those in the double-blind phase.

\section{Efficacy results}

Primary. After 4 weeks of open-label treatment with valsartan $160 \mathrm{mg}$, the mean reduction in MSDBP was $10.0 \mathrm{~mm} \mathrm{Hg}$. The reduction in MSDBP between the beginning of open-label phase (week -4) and the end of double-blind phase (week 4) was greater in the valsartan $320 \mathrm{mg}$ group $(12.0 \mathrm{~mm} \mathrm{Hg})$ compared with the valsartan $160 \mathrm{mg}$ group $(10.7 \mathrm{~mm} \mathrm{Hg})$ in the overall ITT population (Figure 2).

Mean least square reduction in MSDBP over the double-blind phase (week 4 vs. week 0 ) was significantly $(P<0.0001)$ greater in the valsartan $320 \mathrm{mg}$ group $(1.6 \mathrm{~mm} \mathrm{Hg}$ ) than in the valsartan $160 \mathrm{mg}$ group $(0.5 \mathrm{~mm} \mathrm{Hg})$ (Table 2). Similar results were obtained in the per-protocol population (not shown).

Secondary and tertiary. In the population not controlled by initial treatment, the reduction from baseline (week 0) to end point (week 4) in MSDBP was significantly greater in the valsartan $320 \mathrm{mg}$ group compared with the valsartan $160 \mathrm{mg}$ group. Although in this population the MSDBP change from baseline was $-2.8 \mathrm{~mm} \mathrm{Hg}$ for valsartan $160 \mathrm{mg}$ and $-4.1 \mathrm{~mm} \mathrm{Hg}$ for valsartan $320 \mathrm{mg}$, a tendency for BP to increase was conversely seen in controlled subjects, being less pronounced in the $320 \mathrm{mg}$ than in the $160 \mathrm{mg}$ group $(+0.9 \mathrm{~mm} \mathrm{Hg}$ and $+2.0 \mathrm{~mm} \mathrm{Hg}$, respectively). Valsartan $320 \mathrm{mg}$ was thus more effective than valsartan $160 \mathrm{mg}$ in both strata (Table 2; Figure 2).

In the overall population, after 4 weeks of open-label treatment with valsartan $160 \mathrm{mg}$, the mean reduction in MSSBP was $12.3 \mathrm{~mm} \mathrm{Hg}$. In the double-blind phase, this effect was maintained in the valsartan $160 \mathrm{mg}$ group ( $13.0 \mathrm{~mm} \mathrm{Hg}$ reduction $v s$. visit 2 ), and became more pronounced $(16.1 \mathrm{~mm} \mathrm{Hg}$ reduction vs. visit 2) in patients who switched to valsartan $320 \mathrm{mg}$. The mean reductions in the doubleblind phase were significantly greater in the valsartan $320 \mathrm{mg}$ group compared with the valsartan $160 \mathrm{mg}$ group in the overall ITT population, in both study strata (Table 2; Figure 2).

In the double-blind phase, mean seated pulse pressure was reduced in all groups and this reduction was larger in the subjects on valsartan $320 \mathrm{mg}$ than in those on valsartan $160 \mathrm{mg}$ (overall: $-1.7 \mathrm{vs}$. $-0.3 \mathrm{~mm} \mathrm{Hg}, \quad P<0.001$; not controlled: -2.0 vs. $-0.7 \mathrm{~mm} \mathrm{Hg}$, $P<0.01$; controlled: -1.7 vs. $-0.1 \mathrm{~mm} \mathrm{Hg}, P<0.001$ ).

Control rates. In the overall ITT population, all control and response rates at the end of the double-blind phase were significantly higher in the valsartan $320 \mathrm{mg}$ group than in the valsartan $160 \mathrm{mg}$ 
Assessed for eligibility $(n=6035)$

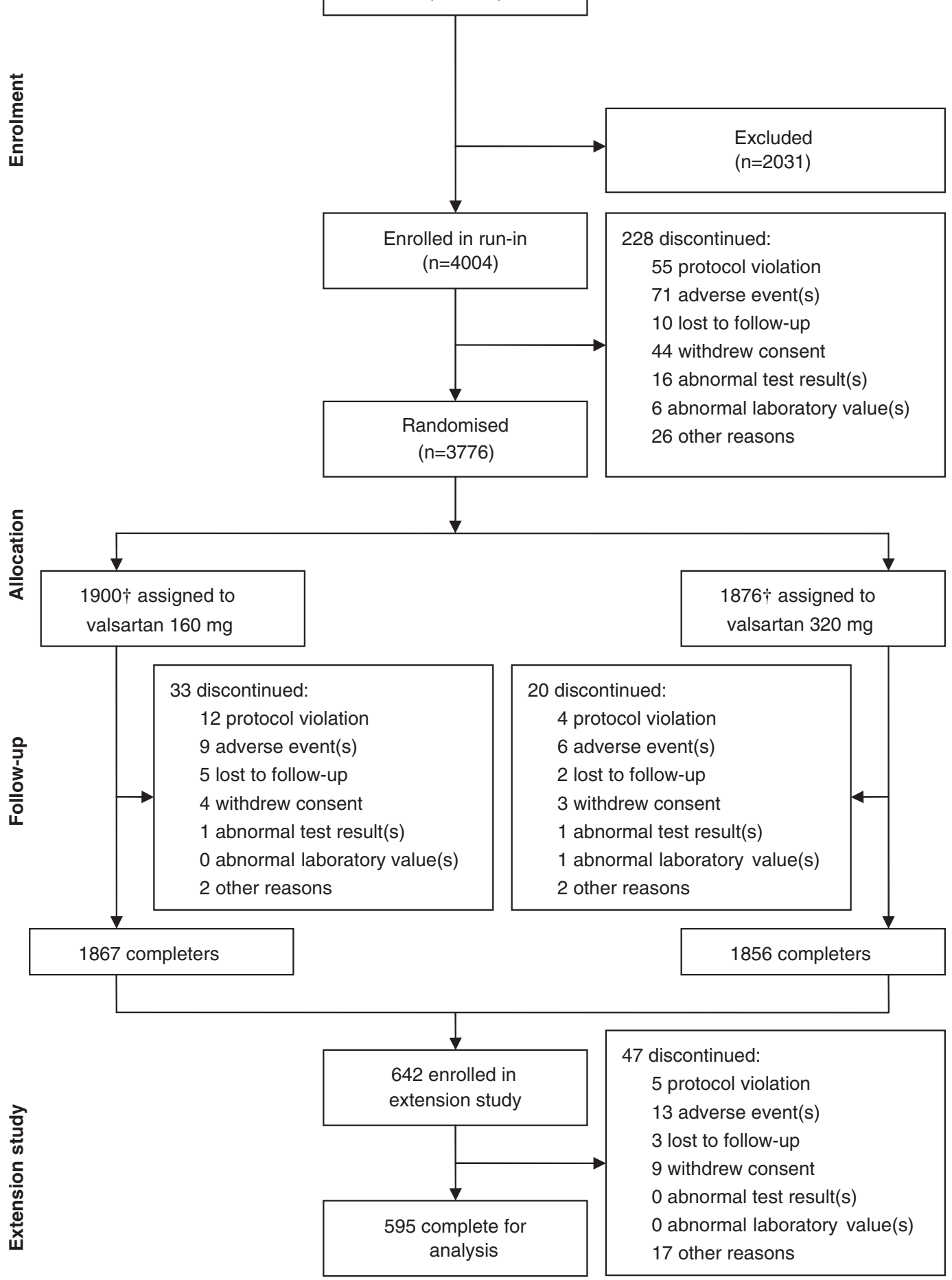

$\uparrow$ A total of 19 randomized patients were excluded from the double-blind intention-to.treat population for not having at least one post-baseline efficacy measurement (16 from the valsartan $160 \mathrm{mg}$ group, and 3 from the valsartan $320 \mathrm{mg}$ group, resulting in an ITT population of 1884 and 1873 patients respectively)

Figure 1 Flow of subjects within the trial.

group (Figure 3). This was true for both study strata and the highest rates were observed in subjects controlled by the initial $160 \mathrm{mg}$ therapy.
Extension phase. Summary statistics for MSDBP and MSSBP are presented by extension visit (weeks 8, 16, 24 and 32) in Table 3. Mean reductions from baseline (week 0 ) of approximately $3-4 \mathrm{~mm} \mathrm{Hg}$ for 
Table 1 Demographics and background characteristics by treatment group (intention-to-treat population)

\begin{tabular}{|c|c|c|c|c|}
\hline Variable & Statistic & $\begin{array}{l}\text { Valsartan } 160 \mathrm{mg} \\
\quad(\mathrm{N}=1884)\end{array}$ & $\begin{array}{l}\text { Valsatan } 320 \mathrm{mg} \\
\quad(\mathrm{N}=1873)\end{array}$ & $\begin{array}{c}\text { Total } \\
(\mathrm{N}=3757)\end{array}$ \\
\hline Age (years) & Mean (s.d.) & $55.2(10.15)$ & $54.6(10.48)$ & $54.9(10.32)$ \\
\hline Age group & $\geqslant 65$ years & 351 (18.6\%) & 331 (17.7\%) & $682(18.2 \%)$ \\
\hline \multirow[t]{2}{*}{ Sex } & Male & $1041(55.3 \%)$ & 1059 (56.5\%) & 2100 (55.9\%) \\
\hline & Female & 843 (44.7\%) & 814 (43.5\%) & 1657 (44.1\%) \\
\hline \multirow{2}{*}{ Race } & Oriental & $6(0.3 \%)$ & $12(0.6 \%)$ & $18(0.5 \%)$ \\
\hline & Other & $193(10.2 \%)$ & $201(10.7 \%)$ & 394 (10.5\%) \\
\hline BMI $\left(\mathrm{kg} \mathrm{m}^{-2}\right)$ & Mean (s.d.) & $28.8(4.66)$ & $29.0(4.45)$ & $28.9(4.56)$ \\
\hline \multirow[t]{2}{*}{ Earlier AHT treatment } & Yes & $1240(65.8 \%)$ & $1223(65.3 \%)$ & $2463(65.6 \%)$ \\
\hline & No & $644(34.2 \%)$ & $650(34.7 \%)$ & $1294(34.4 \%)$ \\
\hline \multicolumn{5}{|l|}{ BP enrolment (V2) } \\
\hline MSSBP $(\mathrm{mm} \mathrm{Hg})$ & Mean (s.d.) & $146.3(15.72)$ & $146.4(15.76)$ & $146.4(15.73)$ \\
\hline $\operatorname{MSDBP}(\mathrm{mm} \mathrm{Hg})$ & Mean (s.d.) & $89.8(8.85)$ & $89.7(9.01)$ & $89.7(8.93)$ \\
\hline
\end{tabular}

Abbreviations: AHT, antihypertensive; BMI, body mass index; BP, blood pressure; MSDBP, mean seated diastolic blood pressure; MSSBP, mean seated systolic blood pressure; s.d., standard deviation.

The data in per protocol population (3560 patients including 1796 in valsartan $160 \mathrm{mg}$ group and 1764 in valsartan $320 \mathrm{mg}$ group) did not differ substantially.
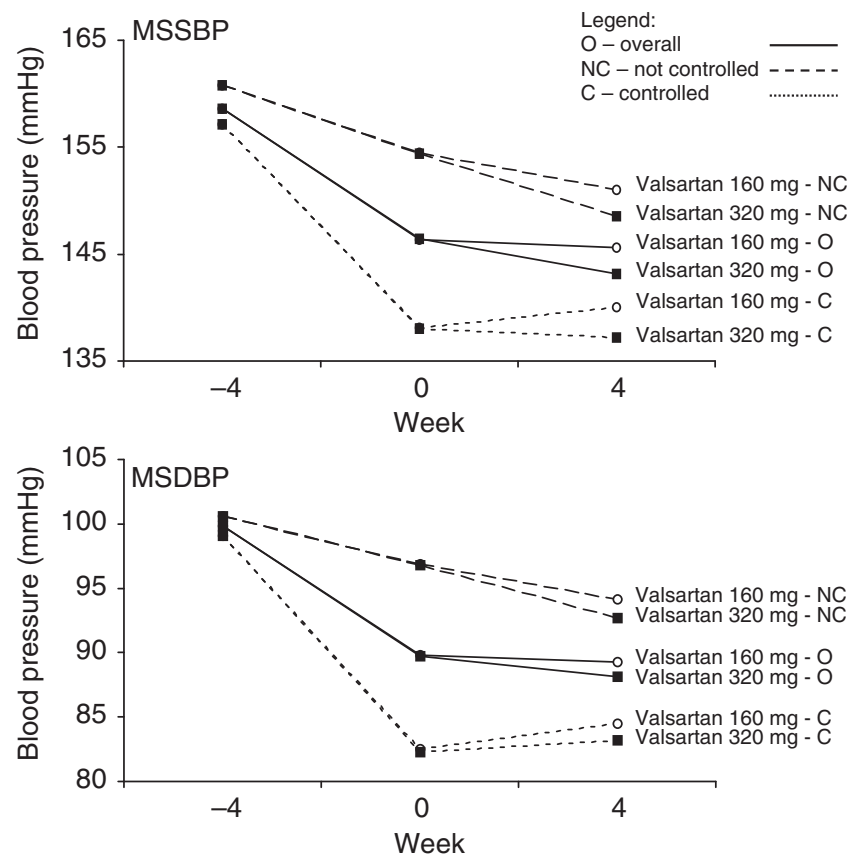

Figure 2 Efficacy results: change from visit 2 to 3 and 4 in mean seated systolic (MSSBP) and diastolic blood pressure (MSDBP) in the overall intention-to-treat (ITT) population, in both study strata.

MSDBP and $5-7 \mathrm{mmHg}$ for MSSBP were observed at each visit, showing maintenance of therapeutic effect. The overall diastolic responder and diastolic control rates at the end of the extension study were 69.4 and $66.7 \%$, respectively.

Few patients made use of additional antihypertensive medications during the extension phase, although there were no restrictions in this regard. The most frequently used antihypertensive drugs during the extension period were thiazides $(4.0 \%$ of extension study participants), dihydropyridine calcium antagonists $(3.3 \%)$ and selective $\beta$-blockers (2.0\%).

\section{Safety results and compliance}

AEs occurred in $15.2 \%$ of the patients during the open-label phase. In the double-blind phase, $\mathrm{AE}$ rates were similar in both arms $(14.2 \%$ both), headache being the most frequently reported individual $\mathrm{AE}$ ( $1.4 \%$ in both groups), followed by nasopharyngitis, dizziness and back pain. There was no evidence of dose dependency in any of the most frequently reported AEs. In the extension phase, AEs occurred in $46.3 \%$ of subjects with the AE incidence rates similar as in the doubleblind phase. Bronchitis was the most frequently reported individual $\mathrm{AE}(3.6 \%)$, followed by back pain, eczema and nasopharyngitis.

Few patients had AEs suspected to be study drug related (4.3\% runin, $2.5 \%$ double blind, $1.9 \%$ extension phase), the most frequent being headache and dizziness in the run-in phase and in the double-blind phase (Table 4) and vertigo; dry mouth and postural dizziness (each $<0.3 \%)$ in the extension phase. Serious AEs occurred in $62(1.6 \%)$ patients during the entire study, none of them suspected to be study drug related. The most frequent serious adverse events were prostate cancer (three patients) and serious hypertension (four patients). No deaths occurred during the study.

Ninety-nine patients (2.5\%) were discontinued because of AEs during the entire study with similar frequency in both treatment groups. Discontinuations because of laboratory abnormalities occurred in six patients $(0.1 \%)$ during the open-label phase and in one patient during the double-blind phase.

In the double-blind phase, low $(<80 \%)$ compliance with study treatment was reported in 37 patients $(1.0 \%)$.

\section{DISCUSSION}

Combination therapy is increasingly recommended as the most appropriate antihypertensive treatment strategy for most subjects. ${ }^{1,2}$ This is based to a large extent on (1) the beneficial pharmacodynamic 
Table 2 Efficacy outcomes-least-square mean sitting BP change (standard error) in the double-blind phase of the study (between week 0 and 4)

\begin{tabular}{|c|c|c|c|c|c|}
\hline \multirow[b]{2}{*}{ Variable } & \multicolumn{2}{|c|}{ Valsartan $160 \mathrm{mg}(\mathrm{N}=1884)$} & \multicolumn{2}{|c|}{ Valsartan 320 mg $(\mathrm{N}=1873)$} & \multirow[b]{2}{*}{ Difference in BP change } \\
\hline & $B P$ at visit 3 & BP change & $B P$ at visit 3 & $B P$ change & \\
\hline \multicolumn{6}{|l|}{$M S D B P(m m ~ H g)$} \\
\hline Overall $(N=3757)$ & 89.8 & $-0.5(0.18)$ & 89.7 & $-1.6(0.18)$ & $1.18(0.23)^{*}$ \\
\hline Not controlled $(N=1902)$ & 96.9 & $-2.8(0.25)$ & 96.8 & $-4.1(0.25)$ & $1.29(0.32)^{*}$ \\
\hline Controlled $(N=1855)$ & 82.5 & $2.0(0.31)$ & 82.3 & $0.9(0.31)$ & $1.10(0.33)^{*}$ \\
\hline \multicolumn{6}{|l|}{ MSSBP (mm Hg) } \\
\hline Overall $(N=3757)$ & 146.3 & $-0.7(0.31)$ & 146.4 & $-3.3(0.31)$ & $2.59(0.40)^{*}$ \\
\hline Not controlled ( $N=1902)$ & 154.5 & $-3.5(0.54)$ & 154.4 & $-5.9(0.53)$ & $2.46(0.57)^{*}$ \\
\hline Controlled $(N=1855)$ & 138.1 & $1.9(0.53)$ & 138.0 & $-0.8(0.54)$ & $2.68(0.58)^{*}$ \\
\hline
\end{tabular}

Abbreviations: BP, blood pressure; MSDBP, mean seated diastolic blood pressure; MSSBP, mean seated systolic blood pressure.

${ }^{*} P<0.001$ for difference in BP change between groups.

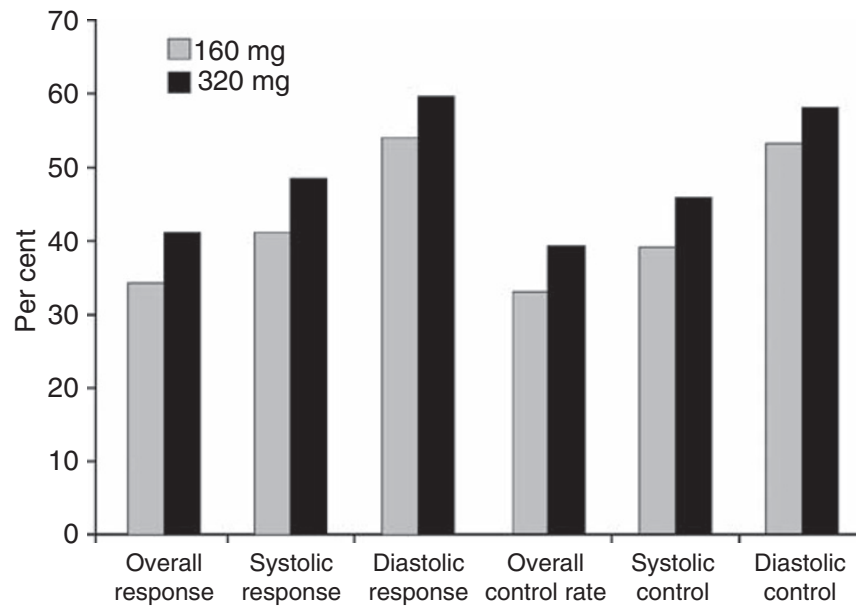

Figure 3 Rates of adequate control of MSDBP, MSSBP or both at the end of the double-blind phase (overall response: MSSBP $<140 \mathrm{~mm} \mathrm{Hg}$ or a reduction of $\geqslant 20 \mathrm{~mm} \mathrm{Hg}$ in MSSBP from baseline, and MSDBP $<90 \mathrm{~mm} \mathrm{Hg}$ or a reduction of $\geqslant 10 \mathrm{~mm} \mathrm{Hg}$ in MSDBP from baseline; systolic response: MSSBP $<140 \mathrm{~mm} \mathrm{Hg}$ or a reduction of $\geqslant 20 \mathrm{~mm} \mathrm{Hg}$ from baseline; diastolic response: MSDBP $<90 \mathrm{~mm} \mathrm{Hg}$ or a reduction of $\geqslant 10 \mathrm{~mm} \mathrm{Hg}$ in MSDBP from baseline; overall control: MSSBP $<140 \mathrm{~mm} \mathrm{Hg}$ and MSDBP $<90 \mathrm{~mm} \mathrm{Hg}$; systolic control: MSSBP $<140 \mathrm{~mm} \mathrm{Hg}$; diastolic control: MSDBP $<90 \mathrm{~mm} \mathrm{Hg}$ ).

Table 3 Efficacy outcomes-least-square mean seated blood pressure change from baseline in the extension phase of the study

\begin{tabular}{|c|c|c|c|c|c|c|c|}
\hline \multirow[b]{2}{*}{ Week } & \multirow[b]{2}{*}{$\mathrm{N}$} & \multicolumn{2}{|c|}{ Visit 3 (mm Hg) } & \multicolumn{2}{|c|}{ Post (mm Hg) } & \multicolumn{2}{|c|}{ Change ( $\mathrm{mm} \mathrm{Hg}$ ) } \\
\hline & & $M S D B P$ & MSSBP & $M S D B P$ & $M S S B P$ & $M S D B P$ & MSSBP \\
\hline 8 & 638 & 89.7 & 149.4 & 86.8 & 144.6 & -2.97 & -4.83 \\
\hline 16 & 619 & 89.7 & 149.2 & 85.5 & 143.0 & -4.19 & -6.14 \\
\hline 24 & 602 & 89.6 & 149.1 & 85.3 & 141.5 & -4.31 & -7.63 \\
\hline 32 & 598 & 89.6 & 149.2 & 85.9 & 142.1 & -3.66 & -7.10 \\
\hline
\end{tabular}

Abbreviations: MSDBP, mean seated diastolic blood pressure; MSSBP, mean seated systolic blood pressure.

interactions between selected drug classes both in terms of efficacy and $\mathrm{AEs}^{13}$ and (2) on the observation that for many drugs in their highdose range further increasing the dosage leads to a fast increase in side effects and little further benefit in terms of therapeutic effect. ${ }^{5}$
Table 4 Number (\%) of patients with most frequently reported $(\geqslant 0.2 \%$ in either group) adverse events that were suspected to be related to administration of study drug (safety population, double-blind phase)

\begin{tabular}{lcc}
\hline Adverse events & $\begin{array}{c}\text { Valsartan 160 mg, } \\
\mathrm{N}=1898, \mathrm{n}(\%)\end{array}$ & $\begin{array}{c}\text { Valsartan } 320 \mathrm{mg}, \\
\mathrm{N}=1876, \mathrm{n}(\%)\end{array}$ \\
\hline $\begin{array}{l}\text { Total number of patients with } \\
\text { suspected drug-related }\end{array}$ & $45(2.4)$ & $48(2.6)$ \\
$\begin{array}{l}\text { adverse events } \\
\text { Headache }\end{array}$ & $7(0.4)$ & $10(0.5)$ \\
Dizziness & $4(0.2)$ & $5(0.3)$ \\
Vertigo & $1(0.1)$ & $4(0.2)$ \\
Asthenia & $1(0.1)$ & $3(0.2)$ \\
Weight increased & $6(0.3)$ & $3(0.2)$ \\
Fatigue & $3(0.2)$ & $3(0.2)$ \\
Diarrhea & $3(0.2)$ & $2(0.1)$ \\
\hline
\end{tabular}

The latter concept, undoubtedly true for some drugs, should not be readily extrapolated to new, safer agents, including ARBs, unless scientific data indicate so. In fact, a monotherapy-based approach to hypertension treatment might still be considered as a valuable option in treating hypertension in appropriate patients because of its simplicity and ability to reduce the risk of class-specific dose-independent side effects. This, however, should be supported by a demonstration for individual drugs of their efficacy and safety at high doses. ValTop is the first study to provide such a demonstration for valsartan used in monotherapy in uncomplicated mild and moderate hypertensive subjects. Its results are reinforced by the fact that BP measurement was performed using an automated device, which provides more stable and less biased values. ${ }^{11}$

The efficacy of valsartan in lowering BP is well known ${ }^{14,15}$ and was confirmed in the open-label phase of this study, in which a $10 \mathrm{~mm} \mathrm{Hg}$ reduction in DBP was induced by $160 \mathrm{mg}$ dose of valsartan. The main result of this study is that in subjects randomized to an up-titration to $320 \mathrm{mg}$ dose after 4 weeks of open-label treatment, further reduction occurred in both SBP and DBP (the reductions were, respectively, larger by 2.59 and $1.18 \mathrm{~mm} \mathrm{Hg}$, compared with patients remaining on $160 \mathrm{mg}$ valsartan). This translated into an additional $6.2 \%$ of subjects who achieved both SBP and DBP control when treated with the $320 \mathrm{mg}$ dose, meaning that in 1 out of 10 patients uncontrolled with the initial dosage, a therapeutic success can be achieved with high-dose monotherapy. ${ }^{16}$ Obviously, the size of additional BP-lowering effect 
achieved by doubling valsartan dose was smaller compared with what was observed when hydrochlorothiazide or amlodipine were added to valsartan. ${ }^{17-19}$ However, the aim of our study was not to undermine the usefulness of combination therapy in achieving BP control, but rather to show that, in a number of subjects, using the same $\mathrm{ARB}$ as a high-dose monotherapy may be sufficient to achieve the therapeutic target.

Although the BP changes observed in ValTop are in line with the dose-response curve described in other studies, ${ }^{14,15}$ ValTop provides a deeper insight into the characteristics of response to increasing dosages of valsartan. It shows that the additional, dose-dependent effect of valsartan $320 \mathrm{mg}$ on BP was not confined to subjects who attained BP control with the initial $160 \mathrm{mg}$ dose, but that a similar effect was also present in the not controlled stratum. This indicates that subjects, in whom the smaller dose of valsartan produces a minor BP-lowering effect and who would thus normally be switched to another medication, may still attain a significant BP-lowering effect with an early, aggressive up-titration of valsartan to $320 \mathrm{mg}$. Possibly, such favorable result might also be obtained by starting treatment straightaway with the higher dose of this drug.

In the run-in and double-blind phases of ValTop, the treatment effects were evaluated after 4 weeks of therapy. Many drugs have been reported to induce additional $\mathrm{BP}$ reductions beyond this period; however, in case of valsartan, the additional BP changes after the initial 4 weeks of therapy are small. After further 4 weeks of valsartan monotherapy, they were reported to be approximately $0-1 \mathrm{~mm} \mathrm{Hg}^{20,21}$ Although additional reductions up to $2-3 \mathrm{~mm} \mathrm{Hg}$ have been reported for valsartan/hydrochlorothiazide combination, in most studies, the maximal antihypertensive effect was typically seen within 4 weeks. $^{20-22}$ This is reflected in the current prescribing information for valsartan and valsartan/HCTZ, which states that the antihypertensive effect is substantially present within 2 weeks, and maximal effects are attained within 4 weeks and persist during long-term therapy.

ValTop is one of the first studies performed in a clinical setting $^{14,23,24}$ to explore the safety profile of high-dose ARB in patients without co-morbidities, that is those patients typically seen in everyday clinical practice. In this study, we have shown, in a large population of hypertensive subjects, that valsartan at high doses is safe, the frequency of AEs being similar to that of $160 \mathrm{mg}$. Very few subjects $(<5 \%)$ experienced AEs that appeared to be drug related (mostly headache) and none of those was classified as serious. There were only seven cases of laboratory abnormalities that led to discontinuation of therapy, none of which were related to any serious $\mathrm{AEs}$, and did not appear to be related to drug properties. In particular, no cases of clinically significant renal function impairment were observed.

The extension phase of ValTop showed that BP values did not show any tendency toward an escape phenomenon, but that they actually decreased further over time, with tolerability profile that remained excellent. This clearly indicates that high-dose valsartan in monotherapy is both safe and effective in mild-to-moderate uncomplicated hypertensive patients over relatively long periods of time.

The findings of ValTop may further stimulate the research on the clinical usefulness of high-dose ARBs. Several studies ${ }^{6,7,9,10,25-28}$ have indicated that in high-risk populations, ARBs at high doses may offer cardiovascular or renal protection despite, and independently of modest additional BP reductions compared with standard dosages. Although similar BP pattern was seen in ValTop in uncomplicated hypertensive subjects, it remains to be seen whether additional,
BP-independent benefits of high dosages of ARB also present in this setting.

\section{Conclusions}

ValTop study shows that high doses of valsartan can be safely and effectively administered in uncomplicated mild-to-moderate hypertensive subjects, irrespectively of the initial control obtained with a moderate dosage. From a clinical perspective, our data suggest that if a patient on the initial $160 \mathrm{mg}$ dose is not sufficiently controlled, an attempt to use the higher dosage may be a reasonable therapeutic approach. We believe that the best candidates to this strategy are those patients who are close to target BP while on $160 \mathrm{mg}$ dose and/or in whom the physician is reluctant to add another drug for a variety of reasons (patient's preference, risk of non-compliance, side effects or interactions with other drugs). Therefore, high-dose ARB monotherapy should remain a viable option in hypertension management. Further research is needed to show whether high-dose ARBs provide any BP-independent benefits in uncomplicated hypertension and to evaluate their usage in combination with other antihypertensive agents, for example diuretics.

\section{CONFLICT OF INTEREST}

Albert Kandra and Robert Di Giovanni are employees of Novartis Pharma AG, the sponsor of the trial.

\section{ACKNOWLEDGEMENTS}

The trial was supported by an unrestricted grant from Novartis Pharma AG.

1 Mancia G, De Backer G, Dominiczak A, Cifkova R, Fagard R, Germano G, Grassi G, Heagerty AM, Kjeldsen SE, Laurent S, Narkiewicz K, Ruilope L, Rynkiewicz A, Schmieder RE, Boudier HA, Zanchetti A, Vahanian A, Camm J, De Caterina R, Dean V, Dickstein K, Filippatos G, Funck-Brentano C, Hellemans I, Kristensen SD, McGregor K, Sechtem U, Silber S, Tendera M, Widimsky P, Zamorano JL, Erdine S, Kiowski W, Agabiti-Rosei E, Ambrosioni E, Lindholm LH, Viigimaa M, Adamopoulos S, AgabitiRosei E, Ambrosioni E, Bertomeu V, Clement D, Erdine S, Farsang C, Gaita D, Lip G, Mallion JM, Manolis AJ, Nilsson PM, O’Brien E, Ponikowski P, Redon J, Ruschitzka F, Tamargo J, van Zwieten P, Waeber B, Williams B, Management of Arterial Hypertension of the European Society of Hypertension; European Society of Cardiology. 2007 Guidelines for the Management of Arterial Hypertension: The Task Force for the Management of Arterial Hypertension of the European Society of Hypertension (ESH) and of the European Society of Cardiology (ESC). J Hypertens 2007; 25: 1105-1187.

2 Chobanian AV, Bakris GL, Black HR, Cushman WC, Green LA, Izzo Jr JL, Jones DW, Materson BJ, Oparil S, Wright Jr JT, Roccella EJ, Joint National Committee on Prevention, Detection, Evaluation and Treatment of High Blood Pressure. National Heart, Lung, and Blood Institute; National High Blood Pressure Education Program Coordinating Committee. The Seventh Report of the Joint National Committee on Prevention, Detection, Evaluation, and Treatment of High Blood Pressure: the JNC 7 report. JAMA 2003; 289: 2560-2572.

3 Hansson L, Zanchetti A, Carruthers SG, Dahlöf B, Elmfeldt D, Julius S, Ménard J, Rahn $\mathrm{KH}$, Wedel $\mathrm{H}$, Westerling S. Effects of intensive blood-pressure lowering and low-dose aspirin in patients with hypertension: principal results of the hypertension optimal treatment (HOT) randomised trial. HOT Study Group. Lancet 1998; 351: 1755-1762.

4 Sharma AM, Wittchen HU, Kirch W, Pittrow D, Ritz E, Göke B, Lehnert H, Tschöpe D, Krause $P$, Höfler M, Pfister H, Bramlage P, Unger T, HYDRA Study Group. High prevalence and poor control of hypertension in primary care: cross-sectional study. J Hypertens 2004; 22: 479-486.

5 Holzgreve $\mathrm{H}$. Combination versus monotherapy as initial treatment in hypertension. Herz 2003; 28: 725-732.

6 Cohn JN, Tognoni G. Valsartan heart failure trial investigators. A randomised trial of the angiotensin-receptor blocker valsartan in chronic heart failure. N Engl J Med 2001; 345: 1667-1675.

7 Pfeffer MA, McMurray JJ, Velazquez EJ, Rouleau JL, Køber L, Maggioni AP, Solomon SD, Swedberg K, Van de Werf F, White H, Leimberger JD, Henis M, Edwards S, Zelenkofske S, Sellers MA, Califf RM. Valsartan, captopril, or both in myocardial infarction complicated by heart failure, left ventricular dysfunction, or both. $N$ Engl J Med 2003; 349: 1893-1906.

8 Dahlöf B, Devereux RB, Kjeldsen SE, Julius S, Beevers G, de Faire U, Fyhrquist F, Ibsen $\mathrm{H}$, Kristiansson K, Lederballe-Pedersen O, Lindholm LH, Nieminen MS, Omvik P, Oparil $\mathrm{S}$, Wedel H, LIFE Study Group. Cardiovascular morbidity and mortality in the losartan 
intervention for endpoint reduction in hypertension study (LIFE): a randomised trial against atenolol. Lancet 2002; 359: 995-1003.

9 Parving HH, Lehnert H, Brochner-Mortensen J, Gomis R, Andersen S, Arner P. The effect of irbesartan on the development of diabetic nephropathy in patients with type 2 diabetes. N Engl J Med 2001; 345: 870-878.

10 Lewis EJ, Hunsicker LG, Clarke WR, Berl T, Pohl MA, Lewis JB, Ritz E, Atkins RC, Rohde R, Raz I, Collaborative Study Group. Renoprotective effect of the angiotensinreceptor antagonist irbesartan in patients with nephropathy due to type 2 diabetes. N Engl J Med 2001; 345: 851-860.

11 Mengden T, Asmar R, Kandra A, Di Giovanni R, Brudi P, Parati G. Use of automated blood pressure measurements in clinical trials and registration studies. Data from the VALTOP study. Blood Press Monit 2009 (in press).

12 El Assaad MA, Topouchian JA, Asmar RG. Evaluation of two devices for self-measurement of blood pressure according to the international protocol: the Omron M5-I and the Omron 705IT. Blood Press Monit 2003; 8: 127-133.

13 Gavras I, Rosenthal T. Combination therapy as first-line treatment for hypertension. Curr Hypertens Rep 2004; 6: 267-272.

14 Pool J, Oparil S, Hedner T, Glazer R, Oddou-Stock P, Hester A. Dose-responsive antihypertensive efficacy of valsartan, a new angiotensin II-receptor blocker. Clin Ther 1998; 20: 1106-1114.

15 Oparil S, Dyke S, Harris F, Kief J, James D, Hester A, Fitzsimmons S. The efficacy and safety of valsartan compared with placebo in the treatment of patients with essential hypertension. Clin Ther 1996; 18: 797-810.

16 Mancia G, Grassi G. Systolic and diastolic blood pressure control in antihypertensive drug trials. J Hypertens 2002; 20: 1461-1464.

17 Mallion JM, Carretta R, Trenkwalder P, Martinez JF, Tykarski A, Teitelbaum I, cOddou P, Fagan T, Co-Diovan Study Group. Valsartan/hydrochlorothiazide is effective in hypertensive patients inadequately controlled by valsartan monotherapy. Blood Press Supp 2003; 1 : 36-43.

18 Tuomilehto J, Tykarski A, Baumgart P, Reimund B, Breton SL, Ferber P. Combination therapy with valsartan/hydrochlorothiazide at doses up to $320 / 25 \mathrm{mg}$ improves blood pressure levels in patients with hypertension inadequately controlled by valsartan 320 mg monotherapy. Blood Press Supp/ 2008; 1: 15-23.

19 Philipp T, Smith TR, Glazer R, Wernsing M, Yen J, Jin J, Schneider H, Pospiech R. Two multicenter, 8-week, randomized, double-blind, placebo-controlled, parallel-group studies evaluating the efficacy and tolerability of amlodipine and valsartan in combination and as monotherapy in adult patients with mild to moderate essential hypertension. Clin Ther 2007; 29: 563-580.

20 Benz JR, Black HR, Graff A, Reed A, Fitzsimmons S, Shi Y. Valsartan and hydrochlorothiazide in patients with essential hypertension. A multiple dose, double-blind, placebo controlled trial comparing combination therapy with monotherapy. J Hum Hypertens 1998; 12: 861-866.

21 Pool JL, Glazer R, Weinberger M, Alvarado R, Huang J, Graff A. Comparison of valsartan/hydrochlorothiazide combination therapy at doses up to $320 / 25 \mathrm{mg}$ versus monotherapy: a double-blind, placebo-controlled study followed by long-term combination therapy in hypertensive adults. Clin Ther 2007; 29: 61-73.

22 Calhoun DA, Lacourcière Y, Chiang YT, Glazer RD. Triple antihypertensive therapy with amlodipine, valsartan, and hydrochlorothiazide: a randomized clinical trial. Hypertension 2009; 54: 32-39.

23 Smith DH, Matzek KM, Kempthorne-Rawson J. Dose response and safety of telmisartan in patients with mild to moderate hypertension. J Clin Pharmacol 2000; 40: $1380-1390$.

24 Kumbasar B, Atlibatur Akbas F, Serez K, Ger E, Uzunoglu S, Ergen K, Ayer M. Highdose exposure to valsartan with suicidal intention. Int J Clin Pharmacol Ther 2004; 42: 328-329.

25 Brenner BM, Cooper ME, de Zeeuw D, Keane WF, Mitch WE, Parving HH, Remuzzi G, Snapinn SM, Zhang Z, Shahinfar S, RENAAL Study Investigators. Effects of losartan on renal and cardiovascular outcomes in patients with type 2 diabetes and nephropathy. N Engl J Med 2001; 345: 861-869.

26 Rossing K, Schjoedt KJ, Jensen BR, Boomsma F, Parving HH. Enhanced renoprotective effects of ultrahigh doses of irbesartan in patients with type 2 diabetes and microalbuminuria. Kidney Int 2005; 68: 1190-1198.

27 Pfeffer MA, Swedberg K, Granger CB, Held P, McMurray JJ, Michelson EL, Olofsson B, Ostergren J, Yusuf S, Pocock S, CHARM Investigators and Committees. Effects of candesartan on mortality and morbidity in patients with chronic heart failure: the CHARM-Overall programme. Lancet 2003; 362: 759-766.

28 Hollenberg NK, Parving HH, Viberti G, Remuzzi G, Ritter S, Zelenkofske S, Kandra A Daley WL, Rocha R. Albuminuria response to very high-dose valsartan in type 2 diabetes mellitus. J Hypertens 2007; 25: 1921-1926.

\section{APPENDIX}

list of participating countries and investigators

Argentina: LM Amuchastegui, M Arnolt, A Astesiano, J Bono, C Kotliar, OR Montaña, P Rodenas, P Rodriguez, AS Villamil, JA Volmaro.

Belgium: K Cornelli, F Coucke, F d'Argent, M Goetinck, A Hutsebaut, R Leliaert, R Lins, G Mehuys, J Meurant, S Ramael, $\mathrm{H}$ Van Aerde, D Van de Looverbosch, D Vanroyen, J Vernijns, F Vrancken, G Watté
Brazil: A Alessi, FA Almeida, MA Baptista, MS Cerci, P Leaes, G Reis, AB Ribeiro.

Canada: I Campbell, S Coyle, M Csanadi, D Dattani, G Girard, R Horner, M Kazimirski, J Kooy, Y Lacourciere, BH Lasko, JH Lenis, B Ramjattan, D Sinclair, DI Stewart.

Colombia: G Parra, C Rincon, JC Velasquez.

Czech Republic: P Brejník, J Dosedel, P Herle, A Linhart, E Pederzoliova, V Skalnikova, T Sklenar.

Denmark: JV Andersen, K Borch, N Gerdes, P Hein, JA Kristensen, K Lawaetz, M Lytje, S Neldam, JH Pedersen, NP Sejr, BS Severinsen, O Skjoldby, TA Sørensen, S Stender, B Uhrenholt, J Vinberg Larsen, C Wulff-Andersen, T Yde.

Ecuador: P Delgado, C Fierro, RP Mármol.

Finland: J Eriksson, I Kantola, J Melin, M Niemi, L Niskanen, J Taurio.

France: R Asmar, J-B Churet, Y Couffin, B Daguzan, G Mongin, H Pradere, P Sauli, F Spilthooren.

Germany: M Abdel Qader, V Adelberger, G Anders, A Ansari, U Armbrecht, G Bachour, K-P Bartfeld, A Bassen-Auf dem Brinke, F Bauer, WF Behrendt, A Biedermann, M Bill, G Blome, H Boeneke, W Bortz, R Breidung, J Breuer, E Brunk, UW Buschmann, H Carboni, P Chueratanakorn, H Daniel, G Dienhart-Schneider, R Doebbeler, P Faust, W Folkerts, W Freudenstein, D Fricke, S Gehlhar, W Geldmacher, K Gerlach, S Gessner, D Glatzel, H-J Graemer, A Grapow, C-M Grimm, W Groeschel, J Grosskopf, A Gruenerbel, H GrueterDegering, M Hanefeld, C Heidenreich, J Hein, K-H Hey, U Hilsmann, A Himpel-Boenninghoff, RU Hoffmann, Y Hoffmann, F-M Isbruch, U Jaeck, J Junggeburth, TS Kammermeier, C Klein, H Klossek, A Kocjan, HJ Kramm, V Kroll, M Lang, R Lehmann, M Lohnstein, I Macarie, G Mahla, H Martens, KP Martin, T Menke, M Mueser, IF Naudts, C Naumann d'Alnoncourt, A Overbeck, L Partenheimer, K-H Pfetsch, J Pohle, U Pustlauk, K-A Rapp, G Rehling, R-M Remppis, $\mathrm{T}$ Riddermann, $\mathrm{R}$ Rippert, $\mathrm{M}$ Roevenich, $\mathrm{N}$ Rose, K Rudolph, M Sahlfeld, H Samer, R Schaetzl, L Schinke, C Schmidt, U Schmidt-Rosenbaum, H Schmitt, J Schmitz, H Schneider, G Scholz, R Schreiber, R Schroeer, I Senftleber, U Siebert, M Sperber, K-D Spreng, M Tekiyeh, S Tisborn, K Tondt, W Tuerk, P Uebel, D Wamhoff, U Werkmeister, G Wiest, P Witzany, M Wunderer, UP Zimmermann.

Great Britain: P Ainsworth, G Chapman, RC Cook, AS Cowie, D Dutchman, J Fraser, A George, C Godfrey, PJ Horn, FR Kingston, A Middleton, J Robinson, M Salman, H Thomas.

Guatemala: JC Arriola, VE Corona, J Fernandez, P Montenegro, R Muñoz, E Rodríguez.

Italy: N Baldi, L Bartolucci, M Borzi, M Boscaro, A Caiazza, R Calabrò, G Canale, V Capuano, R Carretta, G Cerasola, M Cignarelli, G De Ferrari, SM De Tommasi, E Degli Esposti, M Destro, S Di Somma, C Ferri, R Fogari, A Fontanelli, A Gargiulo, R Grassi, A Lagi, F Locatelli, F Magrini, M Maina, A Mainella, E Malacco, E Mannarino, P Margaroli, A Montanari, L Pagano, G Palmieri, D Panuccio, RM Polimeni, L Rossi, M Santonastaso, S Scardi, LA Sechi, E Tascione, G Testa, NA Varì, M Volpe.

Mexico: M Araujo, P Camacho, E Cardona, J Carranza, 1 elizondo, J Esparragoza, M Fernandez, F Flores, P Garcia, V Gonzalez, R Mendirichaga, E Morales, J Parra, A Sanchez, J Verdejo.

Netherlands: T Boermans, PDM Coenen, WA de Backer, HS Emanuels, W Feis, H Ferguson, HL Hoelscher, IR Ong, WMD Salomons, VEKM van de Walle, GHJ van Dijk, HFCM Van Mierlo, JRAY van Rooij, A Veerman, FAAM Vermetten.

Peru: W Cabrera, PR Doig, J Drago, M Horna, PM Salazar, M Zubiate. 
Poland: J Niegowska, A Tykarski, B Wyrzykowski.

Portugal: C Brízido, M Carvalho, C Cotta, V Gomes, A Santana, C Veiga.

Russia: S Boitsov, IE Chazova, J Kobalava, VO Konstantinov, VG Koukes, SB Shoustov, BA Sidorenko, V Zadiontchenko.

Slovakia: A Dukat, J Hromec, P Loviska, J Mazur, Z Mikes, V Smetanova, M Szentivanyi, R Uhliar.

South Africa: C de Hoog, P Mills, R Moodley, V Singh.
Spain: A Altes, M Borrell, L De Teresa, JL Fernandez, J Garcia, J Lafuente, A Ledesma, X Luque, E Marquez, I Montiel, P Morillas, S Narejos, B Pascal, J Plana, X Pujol, J Sobrino, C Suarez, F Valls, JV Vaquer Perez.

Sweden: L Akerman, B Ericsson, B Forslund, B Giver, H Gustafsson, L Haglund, J Holm, A-C Knutsson, D Larsson, A Lindh, H Noppa, P Ronmark, O Sjoberg, S Strid, J-O Svensson, A Theander, C Thorén. Venezuela: A Aveldaño, C Delgado, J Loyo, Y Meza. 